\title{
Yoga and somatic therapy for the treatment of adolescent idiopathic scoliosis: adult case report Marcia Monroe
}

Address: Private practice, 161 West 15th \#3A; New York, NY 10011, USA

Email: Marcia Monroe -marciamnro@aol.com

from 4th International Conference on Conservative Management of Spinal Deformities

Boston, MA, USA. 13-16 May 2007

Published: 12 October 2007

Scoliosis 2007, 2(Suppl I):P7 doi:10.II86/1748-7|6I-2-SI-P7

This abstract is available from: http://www.scoliosisjournal.com/content/2/SI/P7

(c) 2007 Monroe; licensee BioMed Central Ltd.

\section{Objective}

To describe the use of Iyengar Yoga therapy and movement reeducation techniques in the management of a forty-six-year-old woman with idiopathic scoliosis.

\section{Study design}

Case report of a subject diagnosed with idiopathic scoliosis and recommended for spinal fusion during her early adolescent years.

\section{Methods}

The subject instead chose to work with conservative therapy sessions during a one year period. These approaches included somatic movement reeducation techniques, primarily Body Mind Centering, Feldenkrais, and Iyengar Yoga.

\section{Results}

The subject has been studying and teaching on a daily basis Iyengar Yoga classes reinforced with notions of movement reeducation. The Yoga regimen has helped the patient to stabilize weak muscles, enhance the range of respiration, postural tone, as well as strengthen and lengthen the spine through specific postures used as traction. The integration of concepts of movement reeducation based on bio mechanics and motor development has helped the improvement of proprioception, sensibility, and awareness of functional movement.

\section{Conclusion}

The addition oflyengar Yoga therapy regimen with the integration of movement reeducation based on Body Mind Centering and Feldenkrais techniques can be very useful to help the well being and function of victims of scoliosis regardless of age. 